\title{
Marriage and childbirth as factors in school exit: An analysis of DHS data from sub-Saharan Africa
}

Cynthia B. Lloyd

Population Council

Barbara Mensch

Population Council

Follow this and additional works at: https://knowledgecommons.popcouncil.org/departments_sbsr-pgy

Part of the Demography, Population, and Ecology Commons, Family, Life Course, and Society Commons, Gender Equity in Education Commons, and the International Public Health Commons How does access to this work benefit you? Let us know!

\section{Recommended Citation}

Lloyd, Cynthia B. and Barbara Mensch. 2006. "Marriage and childbirth as factors in school exit: An analysis of DHS data from sub-Saharan Africa," Policy Research Division Working Paper no. 219. New York: Population Council. 


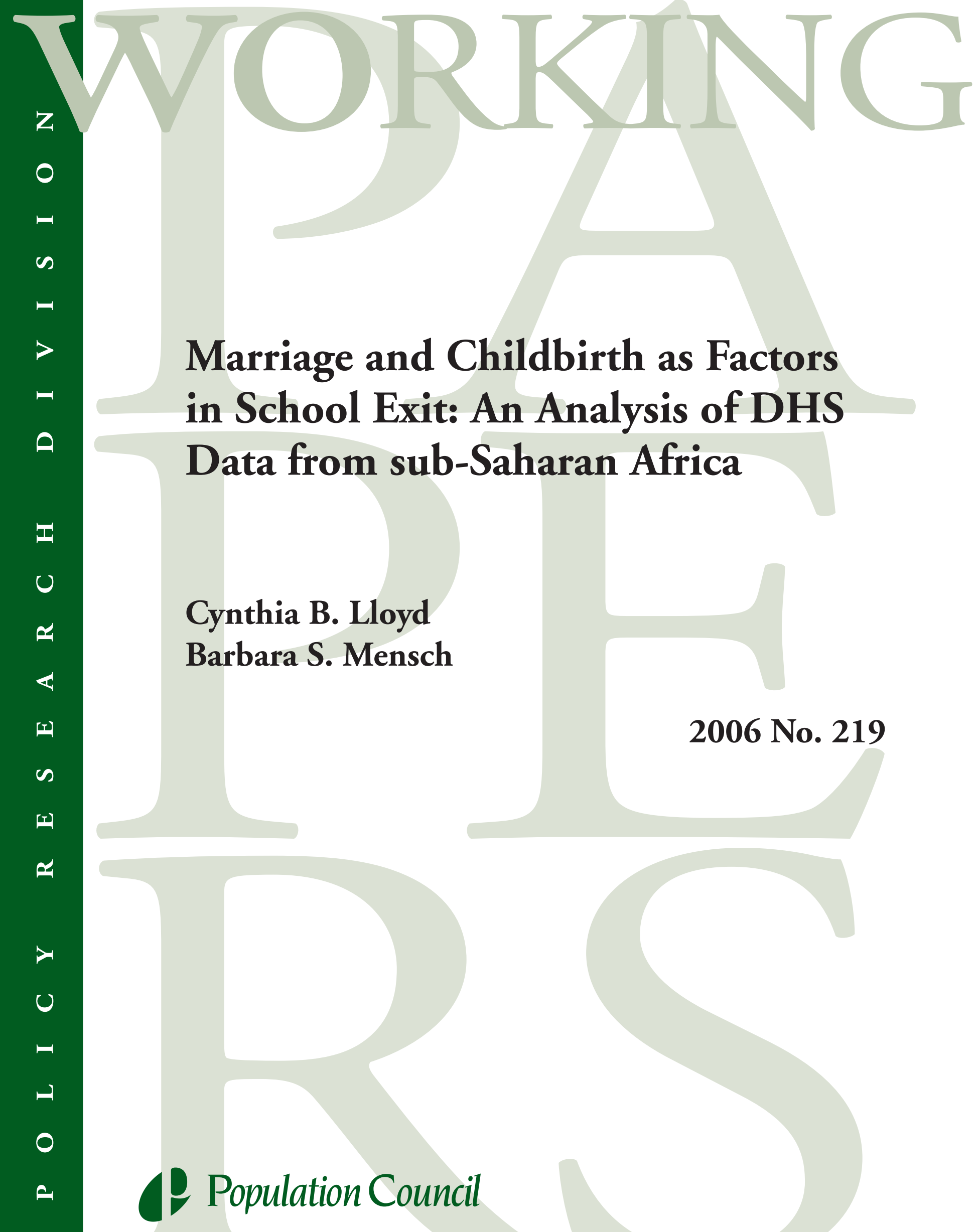




\section{(P) Population Council}

One Dag Hammarskjold Plaza

New York, New York 10017 USA

www.popcouncil.org

pubinfo@popcouncil.org

This material may not be reproduced without written permission from the authors. For a list of Policy Research Division Working Papers, including those that are currently available for downloading in PDF format, see www.popcouncil.org/publications/wp/prd/rdwplist.html.

ISSN: $1554-8538$

(C) 2006 The Population Council, Inc. 


\title{
Marriage and Childbirth as Factors in School Exit: An Analysis of DHS Data from sub-Saharan Africa
}

\author{
Cynthia B. Lloyd \\ Barbara S. Mensch
}

Cynthia B. Lloyd is Director of Social Science Research and Barbara S. Mensch is Senior Associate, Policy Research Division, Population Council, New York.

An earlier version of this paper was presented at the 2006 Annual Meeting of the Population Association of America, Los Angeles, 30 March.

The authors thank Richard Gregory, Barbara Miller, and Monica Grant. They also acknowledge generous financial support for this research from the U.K. Department for International Development and the William and Flora Hewlett Foundation. 


\begin{abstract}
This paper explores the potential importance of marriage and childbirth as determinants of school-leaving in sub-Saharan Africa and identifies some of the common underlying factors that contribute to premature school-leaving and early marriage and childbearing. We find that the risks of leaving school during adolescence for reasons other than childbirth or marriage far exceed the risks associated with these two demographic events. Consistent with overall trends of rising school enrollment and declines in early marriage and childbearing, we also find that the risks of leaving school during adolescence because of childbearing or marriage have declined relative to the past. Among the possible common causes underlying premature departure from school and early marriage and childbearing, our results suggest that delayed ages of school starting - a factor associated with being behind grade for age - could be a factor predisposing girls to a greater likelihood of both leaving school early and early marriage and childbearing. These findings have important policy implications. First, to the extent that demographic events such as early marriage and childbearing trump the school environment as a determinant of school exit during adolescence, our data indicate that early marriage rather than early childbirth is more likely to limit girls' educational horizons, at least in the case of francophone Africa. This result suggests that the reproductive health community should see early marriage as a central area of concern for adolescent reproductive health. Second, our results suggest that "schoolgirl pregnancy" rarely accounts for more than a relatively small percent of girls who leave school. Third, policies that inform parents about the value of starting their children in school on time are likely to have beneficial effects both for grade attainment and for adolescent reproductive health regardless of school quality.
\end{abstract}


Demographers have devoted considerable effort in recent years to exploring the association in developing countries between schooling and fertility (Bledsoe et al. 1999). Education clearly plays a role in the timing of reproductive events. The effect of educational attainment in raising age at marriage and childbearing, and the positive association between current school enrollment and delayed sexual initiation, have been documented with Demographic and Health Survey data (Lloyd 2005). With the rapid expansion of girls' schooling in sub-Saharan Africa, the steady decline in age at puberty, and the greater likelihood of attending school after puberty, the effect of reproductive behavior on school participation among adolescent girls is also now a cause for concern. This concern is magnified by the growing recognition of the importance of secondary schooling for successful transitions to adulthood (Lloyd 2005).

Among policymakers and in the media, marriage and pregnancy are frequently mentioned as reasons for premature school-leaving in the region. Anyone who has lived or traveled in Africa and read the local papers is familiar with the attention given to "schoolgirl pregnancy"- a term that draws attention to the risks schoolgirls face when they stay in school beyond the age of sexual maturity. In most African countries, girls whose pregnancies are detected are required to leave school, at least temporarily. While in some countries rules have been liberalized to provide for the possibility of reentry, the fraction of new mothers returning to school tends to be low. Thus, there is a high cost associated with becoming pregnant while in school. A pregnant schoolgirl typically must make one of two choices: either discontinue her education and go ahead with the pregnancy, or undergo an abortion that is usually illegal, and therefore potentially unsafe, in order to remain in school. Boys who get girls pregnant do not face these same risks and choices.

Child marriage - marriage before 18-is also receiving increasing international attention as both a reproductive health and a children's rights issue. Chief among the arguments made for its elimination is its negative effect on educational attainment. Such claims are not empirically grounded, however. Countries with very early ages at marriage tend to be the same countries where average educational attainment remains well below levels that are likely to conflict with early marriage practices. Hence, in most countries where early marriage is prevalent there is typically a gap of several years between the age when students leave school and the age when they marry (Lloyd 2005). ${ }^{1}$ However, in sub-Saharan Africa, where it is not uncommon for children to begin school late and still be attending primary school in their late teens (Hewett and Lloyd 2005; Mensch and Lloyd 1998) and where girls have experienced recent and dramatic increases in educational participation and attainment, the question of the relationship between early marriage and schooling may be gaining more relevance.

Claims about the importance of pregnancy in causing school exit assume that, were it not for this event, young women would continue in school. Claims that early marriage compromises school attendance make similar assumptions. The problem with assumptions about the link between early marriage and/or early childbearing and schooling is that they overlook the possibility that teenage marriage and/or childbearing may be endogenous to school completion (Mensch et al. 2001; Lloyd and Mensch 1999). 
The same social and economic circumstances that predispose young women to engage in unprotected premarital sex (and subsequently proceed with a pregnancy rather than abort it) and that predispose their families to marry them off at a young age are, in all likelihood, critical factors in early school exit. In short, premature school-leaving among girls may be due less to early marriage or pregnancy than to other factors such as poverty, the perceived value of education, distance to school, safety or quality of the school, or school performance.

This paper is organized in three sections. In the first, we review the limited empirical research on reproductive behavior and premature school-leaving. In the second, we provide descriptive data from the Demographic and Health Surveys (DHS) on school attendance and exit in 20 sub-Saharan countries and construct multiple-decrement life tables of school-leaving to explore the relative importance of different causes of premature departure from school in the five francophone countries where data are available on age at school exit. In particular, we compare reasons given for leaving school with actual demographic events in order to determine what fraction of school departure among adolescents before the completion of secondary school can legitimately be associated with either early marriage or schoolgirl pregnancy. We also explore recent trends in age-specific risks of leaving school as a result of marriage and/or childbearing. Finally, using a discrete-time hazard analysis, we explore some of the potential common underlying factors associated with leaving school and with early marriage and/or childbearing up to age 20, including household poverty, sexual initiation, and an age-forgrade measure of school progress.

\section{REVIEW OF LITERATURE}

There is a small empirical literature on schoolgirl pregnancy; to our knowledge there is no equivalent literature on the relationship between early marriage and school exit. This may be because marriages tend to occur after girls leave school, whereas pregnancies, which ultimately lead to school exit, are more likely to occur while girls are still enrolled. Ironically, however, the "schoolgirl pregnancy" literature is really not about schoolgirl pregnancy at all, but instead about the relationship between school exit and subsequent childbearing. This is the case because there are essentially no data on the number of girls who get pregnant while in school but only data on those who leave school because they are about to give birth. As with marriage, these births tend to occur after school exit rather than while girls are in school. In the discussion below, we review the literature on schoolgirl pregnancy as well as other literature relevant to the questions we plan to address.

Several events need to occur before a girl is in a position to report that pregnancy was the cause of leaving school. First, she must have unprotected or inadequately protected sex while attending school. Second, her pregnancy must be detected while she is still enrolled. Third, she must decide to take the pregnancy to term, thus forgoing the possibility of having an abortion and continuing in school. 
Comparative analysis of DHS data shows that, in a majority of sub-Saharan African countries, the proportion of adolescent girls aged 15-17 who are sexually experienced is much lower among currently enrolled students than among those who never went to school or are no longer in school (Lloyd 2006). Furthermore, adolescent girls who are currently enrolled are much more likely than nonenrolled girls to use contraception if they are sexually active. Findings from a study in Kenya, which links household data on adolescents with data on the characteristics of the schools they attended, provide evidence that the school environment can be a critical factor affecting the likelihood that a schoolgirl will engage in sex. Mensch et al. (2001) found that girls who attended schools where more girls felt they received equal treatment with boys were less likely to have engaged in sex than those who attended schools where fewer girls reported equal treatment. Thus, it appears that the school environment is a factor affecting the likelihood that a girl will be at risk of pregnancy.

It is also possible that the school environment may contribute to a girl's decision to proceed with a pregnancy once detected, but it has been impossible to address this question empirically because of the incompleteness of data on pregnancy. In nationally representative household-based surveys, such as the DHS, it is likely that many pregnancies that occur among schoolgirls go unreported, even when great care is taken to collect data not just on live births but on all pregnancies. The limited data we have on abortion, however, appear to support the view that, among pregnancies that occur during the adolescent years, those that involve schoolgirls are more likely to be aborted than those that involve adolescents who are no longer in school, because pregnancies among schoolgirls are less likely to be wanted.

In in-depth surveys with a focus on abortion, including hospital and clinic-based studies of women who have experienced complications from induced abortion, young women often state their desire to remain in school as a major reason for the abortion. In three of four surveys collected in sub-Saharan Africa with data on the main reason for abortion (Kenya, Nigeria, and Zambia), ${ }^{2}$ between 30 and 55 percent of women reported that "having a child would disrupt education or job" as the primary reason (Bankole et al. 1998). Because, to the best of our knowledge, the majority of women obtaining abortions in Africa are young and unmarried (Bankole et al. 1998), such reasons are more likely to be cited by African women than by women in other regions.

Recent studies from Cameroon provide further support for the finding that abortions among young people are more likely to occur to those who become pregnant while in school than to those who have never attended school or have left school. In a small but representative survey of 384 young people aged 20-29 living in Yaoundé, Calvès (2002) found that being in school increased the odds sevenfold that a pregnancy would result in abortion, after controlling for other factors. This finding is in a context where abortion is illegal but nonetheless widely practiced. In Calvès's sample, 20 percent of young women reported having had an abortion. In a small survey of 184 Beti women of reproductive age who had completed one year of Catholic secondary school, JohnsonHanks (2002) found that almost 70 percent of reported abortions had occurred among women who were enrolled in school at the time of pregnancy. 
Two studies have investigated the degree to which pregnancy-related school departure is a major source of gender differences in educational attainment; the goal was to determine whether policies designed to reduce unintended teenage fertility in school could provide an effective approach to achieving gender equity in school participation. This research, based on the experiences of women who have ever attended school, relies on self-reports on the reasons for leaving school. In the first study, Eloundou-Enyegue (2004) draws on his own rich data from Cameroon with retrospective schooling and pregnancy histories and concludes that pregnancies in secondary school make an important contribution to the gender gap in educational attainment at that level. In the second study, based on a comparative analysis of DHS surveys with data on reasons for leaving school, Eloundou-Enyegue and Stokes (2004) conclude that the relationship between schoolgirl pregnancy and the gender gap in educational attainment, which varies widely across these countries, depends on overall levels of schooling and fertility among adolescents.

These studies suffer from several shortcomings. First, the analysis combined women of all ages, whether they attended school 30 years ago or more recently, despite the fact that schools, social norms, and behaviors are likely to have changed over time in ways that would complicate the interpretation of observed statistical associations. Second, the event of pregnancy was assumed to be exogenous, an implausible assumption for reasons discussed above. Pregnancy could be an ex post justification for leaving school rather than a cause. Third, while the first study was able to draw on a rich data set with retrospective information on all respondents, the second had to derive schooling life tables from cross-sectional data on school participation by age using heroic assumptions about girls' ages at each grade in a context in which late entry and grade repetition are common. These reservations raise questions about the authors' conclusions and suggest the need for a more in-depth exploration of the association between reproductive events such as marriage and/or childbearing and changing patterns of school-leaving.

More recently, Grant and Hallman (2006) have examined prior school performance as a factor in pregnancy-related school exit in South Africa, using data from an adolescent survey conducted in 2001 in KwaZulu-Natal that collected detailed retrospective data on schooling, pregnancy, and births. This is the first study we are aware of that not only uses event history data, permitting precise sequencing of events, but also has explored in a multivariate framework some of the underlying causal factors affecting the likelihood of leaving school, the likelihood of pregnancy while enrolled, and the likelihood of school exit for those who become pregnant while still in school. South Africa is unusual in the subcontinent in having a very high rate of premarital adolescent childbearing, combined with very liberal school policies, allowing pregnant girls and young mothers to stay enrolled in school, as well as child support grants for single mothers. The authors found that poorer school progress and performance as measured by temporary school withdrawal and grade repetition are positively and significantly associated both with the likelihood of getting pregnant while still enrolled and with the likelihood of leaving school if pregnant. 


\section{Marriage ANd ChILdBIRTH AS FACTORS In SCHOOL EXIT}

As noted above, our empirical analysis is based on DHS data. We focus primarily on five francophone countries-Burkina Faso, Cameroon, Côte d'Ivoire, Guinea, and Togo-where data were gathered from all reproductive-age women on their age at leaving school and the main reason for leaving school for those no longer attending. Neither of these two pieces of information is part of the standard DHS questionnaire. To situate these five countries within the wider context of African experience, we begin by comparing them with an additional 15 sub-Saharan African countries where reproductiveage women who were no longer attending school gave reasons for leaving school, although not the age at leaving. Reasons for school exit were reported in all DHS surveys conducted in the late $1990 \mathrm{~s}$, but these questions have subsequently been dropped.

\section{Demographic and educational context}

Table 1 provides descriptive data for the 20 countries on various educational and reproductive outcomes among young women aged 20-24, including the percent of those leaving school who reported pregnancy or marriage as the main reason for leaving. As a check on the quality of data on the main reason for leaving school, we ensure that women reporting marriage or pregnancy had actually been married or given birth by the time of the survey. With the exception of a handful of cases, this proved to be the case. We define "school exit" as any school departure prior to secondary school completion. We chose the age group 20-24 because in most countries young women are no longer enrolled or have completed secondary school by age 20. The 20 countries are ranked from lowest to highest according to the percent who have ever attended school (column 1). Almost the full range of potential levels of school attendance are represented among these countries, from Burkina Faso with 18 percent who ever attended to Zimbabwe and South Africa with 97 and 98 percent. Obviously, the fewer adolescents who have ever attended school, the more selective of the overall population of adolescents will be those in a position to report on the main reason for school departure.

Column 2 provides data on the percent who have left school among those who ever attended. In 14 of the 20 countries, over 80 percent of young women aged 20-24 who ever attended had left school. In the remaining six countries, young women living in South Africa and Nigeria stand out as having relatively low rates of school exit- 37 and 48 percent. In South Africa, 35 percent of young women remain enrolled at these ages (Lloyd 2005). The other women unaccounted for in the departure rate for South Africa can be presumed to have successfully completed secondary school, given the country's nearly universal rate of school enrollment. In Nigeria, the reasons for low school exit rates also include high rates of current enrollment among young women aged 20-24 (19 percent), as well as relatively high rates of secondary school completion among the 68 percent who had ever attended school. Cameroon and Comoros are the only other countries in this group where more than 10 percent of women aged 20-24 are still in school (Lloyd 2005). 
Of young women who left school early, the fraction who reported pregnancy as the main reason ranges from 1 percent in Niger to 31 percent in South Africa (column 3). In 15 of the 20 countries, rates are 10 percent or lower; in nine countries rates are 5 percent or lower. The proportion of those who report marriage as the main reason ranges from 2 percent in Benin, Côte d'Ivoire, and Togo, to between 26 and 28 percent in Chad, Mozambique, and Nigeria (column 4). In 12 countries, rates are 10 percent or lower; in seven countries, they are 5 percent or lower. In most cases, the countries where women report high rates of school exit for marriage are different from the countries where they report high rates of school exit for pregnancy. The countries are roughly evenly divided between those citing marriage and those citing pregnancy as a reason for leaving school.

Next, we categorize countries by low, medium, and high levels of school attendance and prevalence of marriage before age 18 (Table 2) and according to levels of school attendance and prevalence of pregnancy before age 18 (Table 3 ). We note that the five countries featured in our subsequent, more detailed analysis - Burkina Faso, Guinea, Côte d'Ivoire, Cameroon, and Togo — reflect the full range of current experience with respect both to educational participation and to levels of early marriage and childbearing. These countries are italicized in Tables 2 and 3.

In Table 2, we indicate in parentheses the percent who gave marriage as the major reason for leaving school. Regardless of the levels of school attendance or early marriage, we find countries in each cell of the table where no more than 6-7 percent of those who left school reported marriage as the major reason. Not surprisingly the highest values reported among the 20 African countries, including Chad with 28 percent, Mozambique with 26 percent, and Nigeria with 27 percent, are countries where rates of early marriage are in the middle or high category. In Table 3, we also find countries in each cell where 10 percent or less of young women reported pregnancy as a major reason for school exit, even in contexts where enrollment rates and early childbearing rates are moderate to high. Nonetheless, the highest rates occur among the countries that have achieved the highest levels of enrollment.

There are many reasons why countries with similar rates of school participation,

early marriage, and early childbearing might have very different rates of school-leaving attributed to marriage or pregnancy. Among them are different policies on schoolgirl pregnancy, with some countries requiring expulsion, some requiring temporary withdrawal, and some allowing girls to continue in school while they are pregnant, as well as differences in their level of enforcement. A few countries such as Mozambique, Togo, and Mali have very strict policies requiring expulsion; Mali does not allow re-entry after childbirth (Lloyd 2005). At the other extreme is Burkina Faso, where girls who are pregnant are allowed to stay in school throughout their pregnancy and resume immediately after delivery. Most other policies fall somewhere between these extremes.

\section{Multiple-decrement life tables of school exit}

In the five DHS surveys where retrospective data on the age at school exit have been collected as part of the reproductive-age women's questionnaire, we are able to 
construct life tables of school-leaving from age 12 until age 20 for those who were still attending school at age 12. Here again we define school exit as any departure from school that occurs before the completion of secondary school.

Because of the rapid rise in adolescent girls' school attendance in all five countries (Lloyd 2005), we construct separate multiple-decrement life tables for two cohorts of women, those aged 15-24 and those aged 35-44. This allows us to explore trends over a 20 -year period. For each age from 12 through 19, we calculate the overall risk of school exit using childbirth and marriage as the two identified decrements.

We chose age 12 as the starting point because this tends to be the earliest age for the onset of puberty among girls and thus the age at which those still in school are first at risk for pregnancy. The selectivity of the subgroup of women still attending school at age 12 varies widely across these countries because of differences in school attendance rates, although it has lessened over time with rising enrollment. Table 4 presents data on the percentages in school at age 12 for both age cohorts in the five countries.

We compare three alternative estimates of the risk of school exit due to marriage or childbirth. The first estimate is based on the reported reason for leaving school, regardless of whether marriage or a first birth actually took place at the same age at which the student left school. The second estimate is based on the ages reported for school exit, marriage, and childbirth; women who reported that school exit occurred at the same age as or one year before or after giving birth or getting married are deemed to have left school either to give birth or to marry. We attribute the departure in each case to whichever event was reported to have occurred first. Note that although the timing of first marriage (defined by the DHS as age at first cohabitation with a partner or spouse) and first birth is reported in months and calendar years, the timing of school exit is reported as a particular age. Also, even though marriage may precede childbirth and therefore may be the proximate cause of school exit, the marriage could have been precipitated by a pregnancy. However, we know that in these five countries no more than 20 percent of first births took place within seven months of marriage (Lloyd 2005); thus the overwhelming majority were reported to have been conceived within marriage. This second estimate, which allows generous leeway for the sequence of events given the lack of precision in the reported timing of school exit, yields a substantially higher probability than the first. ${ }^{3}$ This higher estimate is partially explained by the fact that women who report a first marriage and/or a first birth during the same year that they report leaving school sometimes provide reasons for leaving other than marriage or pregnancy. The third estimate categorizes a woman's reason for leaving school as childbirth or marriage if she fulfills the criteria applicable to either of the first two estimates. We see the third estimate as a maximum estimate and the first estimate as a minimum estimate of the number of women whose school departure could plausibly be linked to either childbirth or marriage. Our goal is to create upper and lower bounds for the degree to which leaving school is the result of marriage or childbirth.

Table 5 contrasts the results for the three alternative estimates of the cumulative probability of school exit by age 20 for each cause, separately and combined, and for both age groups. All women who reported marriage or pregnancy as the main reason for 
leaving school had in fact been married or had a first birth by the time of the survey. If we compare columns 1 and 2, however, we see that many young women who left school around the time of their first marriage or first child did not provide this as the main reason for leaving school. With the exception of Togo in the case of childbirth, the estimates in column 2 always exceed the estimates in column 1. Because the estimates in column 2 allow for a very generous definition of the cumulative risk of school exit due to either of these demographic events, we might expect very little difference between columns 2 and 3. We might even reasonably assume that column 1 is a subset of column 2. When we combine the two approaches, however, the estimates of school exit attributable to childbirth rise still further, indicating that some women who state that they left school because of pregnancy or marriage reported marriage or childbirth more than one year later or earlier than the age at which they left school. This raises questions about both the validity of reported reasons for leaving school and the accuracy of reporting on the timing of either of these events. The estimates in column 3 include all women who either had experienced childbirth or marriage within one year (on either side of leaving school) or who said that such an event was the major reason for leaving school. We interpret estimate 3 as the upper boundary even though the generous allowance built into it might suggest an overestimate. We deliberately err on the conservative side; it is impossible to know where the truth lies.

Figure 1 depicts results for women aged 15-24 and contrasts estimates 1 and 3 for each cause for all five countries within the context of the overall risks of school exit. The solid line indicates the overall cumulative risk of exit at each age. The gap between that line and the lines for marriage and childbirth indicates the cumulative risk of school exit due to other reasons. Note that no more than 75 percent of women aged 15-24 had left school by age 20 in any country, and no more than 50 percent had done so in Guinea among those who were attending school at age 12 .

If we rely on reported reasons for school departure (estimate 1), we find very low cumulative risks of school exit due to either pregnancy or marriage in all countries, suggesting that young women themselves are very unlikely to give marriage or pregnancy as the main reason for leaving school. The cumulative risk of leaving school for the reported reason of pregnancy ranges from 3 percent in Burkina Faso to 10 percent in Cameroon by age 19, and the cumulative risk of leaving school for the reported reason of marriage ranges from 1 percent in Togo and Côte d'Ivoire to 7 percent in Guinea. Using the most inclusive estimate (3), which combines reasons for leaving school with reported events, the cumulative risk of school departure associated with childbirth ranges from 5 percent in Burkina Faso to 17 percent in Cameroon, and the cumulative risk of school departure associated with marriage ranges from 12 percent in Togo to 22 percent in Cameroon. According to this maximum estimate of school departure attributable to demographic events, marriage is more likely than childbirth to be associated with school exit, whereas the opposite is true if we rely on reported reasons alone. This is largely because, in West and Middle Africa, 82 percent of all births among young women are reported to occur after the date of marriage (Lloyd 2005). Thus the more inclusive 
estimate demonstrates clearly that early marriage is a greater deterrent to school progress than schoolgirl pregnancy in this region of Africa.

Figure 2 shows trends over 20 years in the cumulative risk of school exit from ages 12 to 19 for four of the five countries (excluding Togo) by comparing the cumulative risks for those aged 15-24 to the cumulative risks experienced by those aged 35-44 during this same phase of the life cycle. ${ }^{4}$ In all four countries, the risk of school exit was greater at each age during the late teens for the older age cohort than for the younger cohort. This is the pattern we would expect given rising enrollment rates among young cohorts (Lloyd 2005). The figure also shows trends in the risk of school exit attributable to either marriage or childbirth, using the most inclusive definition, and indicates that school exit due to marriage or childbirth occurs less often now than in the past. This decline is the result of a reduction in the prevalence of adolescent marriage and childbirth over the past 20 years (Lloyd 2005).

\section{Multivariate ANAlysis}

We hypothesize that departure from school and early marriage and childbearing are a common set of behaviors that arise in response to underlying community, familial, and individual norms and circumstances. These norms and circumstances include family income, gender role attitudes (especially attitudes regarding girls' schooling), school availability and quality, as well as individual characteristics such as innate ability and academic performance. Because of these common underlying circumstances, it is not possible to analyze directly the effects of marriage and/or childbirth on the risk of leaving school. Instead, using discrete-time hazard models, we estimate the association between several individual, household, and community factors and the probabilities of school exit, first birth, and first marriage, separately.

Given the constraints of DHS data, our choice of right-hand-side variables is limited. Although certain types of selectivity resulting from background variables are accounted for in the analysis, we recognize that selectivity arising from factors that we cannot observe could still be present. We acknowledge the shortcomings of this analysis but see it as an important first step that we hope will stimulate further research with richer data where available. The sample for these models includes women aged 15-24 at the time of the survey who had been enrolled in school at age 12. This sample is the same as the one used in the previous analysis.

The independent variables include two time-varying variables, age in single years and incidence of premarital sex, which takes the value 0 until first premarital intercourse occurs and the value 1 thereafter. ${ }^{5}$ To measure academic performance, a critical variable in this analysis, we use a grade-for-age index of progress in school calculated as a ratio of the actual number of grades attained relative to the potential number of grades attained if the young woman had started school at the recommended age and remained in school continuously until the year of the survey, if still enrolled, or until the age she left school, if no longer enrolled. Within each country, we assign women who have successfully completed fewer than half of the grades they could have attained to the low category, 
those who completed 50-75 percent of the potential grades to the middle category, and those completing more than 75 percent of the potential grades to the high category. One reason this index is often low in sub-Saharan Africa is that students commonly start school at late ages. Ideally this variable would be time-varying; however, we only have a measure as of the time of leaving school or, if the respondent is still in school, at the time of the interview.

In addition, we include two variables that capture household and family economic and social circumstances - an index of household wealth and the mean grades of school attained by the household head. The index of household wealth, originally developed by Filmer and Pritchett (1999), is based on a set of indicators capturing the ownership of a set of consumer durables as well as various measures of housing quality, including the availability of piped water, electricity, and finished flooring. As per Filmer and Pritchett, households in both the low and middle categories of the index each account for 40 percent of the overall population, while those in the high category account for 20 percent. We were reassured to find that at least three-quarters of young women in each country were still living with parents or other relatives at the time of the survey, suggesting that in most cases current household economic and social status may reasonably be assumed to reflect circumstances during their earlier teenage years. Finally, as a crude proxy for school access, we include a dummy variable for urban residence. In most settings, postprimary schools are far more readily available in urban than in rural areas.

Means for the variables in the logistic regressions are presented in Table 6, and the odds ratios from the hazard models are presented in Tables 7, 8, and 9 for school exit, first marriage, and first birth. The percent having premarital sex before age 20 is around 70-75 percent in Cameroon, Côte d'Ivoire, and Togo but substantially lower - around 42-45 percent - in Burkina Faso and Guinea, countries where the sample of young women who were in school at age 12 is highly selective and where early marriage is much more prevalent. The selectivity of the samples in Burkina Faso and Guinea is also reflected in the much higher percentage in the highest wealth category. While the highest wealth category accounts for 20 percent of the overall population, it accounts for 70 and 64 percent of the sample respectively in Burkina Faso and Guinea. A much higher percentage of young women are in the lowest grade-for-age category (fewer than half the grades completed) in Togo (59 percent versus 6-19 percent), suggesting that, relative to the other four countries, students in Togo get off to a much later start and/or experience higher grade repetition rates. ${ }^{6}$

As expected, the odds of leaving school rise through the teenage years and are considerably higher at older ages (relative to age 12) in Burkina Faso, Cameroon, and Togo. The effects of age are pronounced only at certain ages in Côte d'Ivoire and not at all in the case of Guinea (see Table 7). For all five countries, the odds of leaving school are greater for those who reported having had premarital sex than for those who reported not having had sex before marriage, and the association is statistically significant in all countries but Burkina Faso. As expected, living in an urban area is associated with a reduction in the probability of leaving school early, as is being a member of a household where the head has more schooling. Those living in the wealthiest households are also 
significantly less likely to leave school early. Furthermore, as expected, those with a grade-for-age index less than 0.5 are more likely to leave school. In Cameroon, Côte d'Ivoire, and Togo, women in the lowest category of the grade-for-age index are approximately 1.5 to 1.75 times more likely to leave school, and the association between the lowest grade-for-age index and increased odds of school exit are statistically highly significant. Those in the middle category of the grade-for-age index are also significantly more likely to leave school in Cameroon and Côte d'Ivoire.

For all countries in the sample, the probability of first marriage rises sharply and significantly with age (see Table 8). The odds of first marriage also increase substantially once a young woman has had premarital sex, and the association is statistically significant in all countries but Guinea. Marriage is less likely to occur among women in urban areas and among those from the highest or middle household wealth categories. Education of the household head is not an important factor except in Burkina Faso. Most importantly, except in Guinea, first marriage is more likely to occur during the teenage years among those in the lowest category of the grade-for-age index; in other words, women showing less promise or progress in school or those who started school late are more likely to marry early. The effects of the grade-for-age index are highly significant in Burkina Faso and Cameroon.

We see similar results in the case of first birth (see Table 9). The odds of first birth during the teenage years rise steeply and significantly with age. Because having sex is a necessary though not sufficient condition for having a first birth, having had premarital sex is also positively and highly significantly associated with first birth in all countries. Living in an urban area and being in the highest income group substantially reduce the odds of having a birth. Being in the middle income category is protective as well (with the exception of Burkina Faso), although less so. The education of the household head is not an important factor. Of greatest interest to us were the results of the grade-for-age index of school progress. Being in the lowest category of the grade-for-age index relative to the highest category is associated with an increase in the odds that a young woman will have a first birth during the teenage years in all countries, significantly so in Cameroon and Côte d'Ivoire. In Côte d'Ivoire, being in the lowest category of the grade-for-age index is associated with more than a doubling of the odds of a first birth during the teenage years. Being in the middle category relative to the highest category is associated with increased odds of a first birth in four of the five countries, significantly so in Cameroon. Thus, it appears that a late start or slow progress in school may be an important factor associated with pregnancy and subsequent school exit.

\section{CONCLUSIONS AND IMPLICATIONS}

Among young women from francophone Africa who were still enrolled in school at age 12, the risks of leaving school during adolescence for reasons other than childbirth or marriage far exceed the risks associated with these demographic events. With the exception of Cameroon, where our "maximum estimate" suggests that approximately half 
of the cumulative risk of school exit is associated with childbirth or marriage, this finding is true whether we rely on the reasons women give or on what they say. Moreover, it remains true even when we attribute departure from school to childbirth or marriage in all cases where there is any evidence that childbirth or marriage might be the cause.

Consistent with overall trends of rising school enrollment and declines in early marriage and childbearing, the risks of school exit during adolescence for reasons of childbirth or marriage have declined over time. Combining the two risks, the percentage decline over 20 years in the risk of school exit by age 20 due to childbirth or marriage ranges from 21 percent in Cameroon to 39 percent in Burkina Faso and 56-58 percent in Côte d'Ivoire and Guinea. Looking at childbirth separately, the decline in the risk of leaving school ranges from 9 percent in Cameroon to 47-50 percent in Burkina Faso and Guinea and 66 percent in Côte d'Ivoire. Not only are the risks of school exit due to childbirth greatest in Cameroon, but the decline in the risk has been relatively small compared to the trend in neighboring countries. In most cases, despite an increase in the percentage of adolescents who are still attending school after the age of puberty and a lengthening exposure to the risks of pregnancy with later ages of school exit, the risks of leaving school due to childbirth have nonetheless declined, suggesting the possibility that schooling itself provides young people with a protective environment.

With limited data, we cannot reach firm conclusions about the underlying causes of premature school departure during adolescence. But among those still attending school at age 12, our results suggest that delayed ages of starting school, associated with being behind grade for age, could be a factor predisposing girls to a greater likelihood of both early school exit and early marriage and childbearing. Rather than being a causal factor, however, it could be that parents who place little value on the schooling of their daughters and plan to have them marry early are more likely to send them to school late with the expectation that they will stay in school only through the primary level.

These findings have important policy implications. First, to the extent that demographic events such as early marriage and childbearing trump the school environment as a determinant of school exit during adolescence, our data indicate that early marriage rather than early childbirth is more likely to limit girls' educational horizons, at least in the case of francophone Africa. This result suggests that the reproductive health community should view early marriage as a central area of concern for adolescent reproductive health. Second, our results suggest that "schoolgirl pregnancy" rarely accounts for more than a relatively small percent of girls who leave school. Even in countries like Cameroon, where this topic has received considerable attention, the maximum estimate is that school exit associated with childbirth affects less than one-fifth of girls by age 20 who were still enrolled in school at age 12 . Third, policies that inform parents about the value of starting their children in school on time are likely to have beneficial effects both for grade attainment and for adolescent reproductive health regardless of school quality.

The findings also have implications for future research. A fuller understanding of all factors that contribute to school retention and successful completion of secondary school, to delayed sexual initiation, pregnancy, marriage, and childbirth, and to safer sex 
requires more complete retrospective data. Such data, which include schooling, sexual, and pregnancy histories, would permit an exploration of the conditions that contribute simultaneously to greater schooling success and better adolescent reproductive health. 


\section{NOTES}

1 Cross-sectional data on school-leaving and marriage by single year of age suggest on average roughly a three- to five-year gap between the time 50 percent of young women have left school and 50 percent of them have married (Lloyd 2005).

2 All four surveys included reproductive-age women regardless of marital status. Two were based on small subsamples of women (one of nurses in Kisii, Kenya; the other of 300 Ekiti Yoruba women in Nigeria), and two were hospital/clinicbased studies.

3 In the most extreme cases, this estimate allows a maximum of two years' difference between the timing of school exit and a demographic event.

4 The Togo DHS did not ask the age of school-leaving for those older than age 24 .

5 We recognize that age at first premarital sex could be considered endogenous as it is a behavior that is also responsive to many of the same underlying circumstances. We ran all the hazard models both with and without this variable, and the results for all other variables stayed essentially the same. If premarital sex and another demographic outcome (i.e., school exit or first marriage) were reported to have occurred at the same age, we assumed that the demographic event preceded sexual initiation.

6 According to UNESCO, the recommended age for starting school in Togo is six. However, even if we recalculate the grade-for-age index using age seven as the starting age, the percentage of young people in the lowest grade-for-age category falls by only 10 percentage points to 49 percent, remaining substantially higher than the percentage in other countries. 


\section{REFERENCES}

Bankole, Akinrinola, Susheela Singh and Taylor Haas. 1998. "Reasons why women have induced abortions: Evidence from 27 countries." International Family Planning Perspectives 24(3): 117-127, 152.

Bledsoe, Caroline, John B. Casterline, Jennifer A. Johnson-Kuhn, and John G. Haaga (eds.). 1999. Critical Perspectives on Schooling and Fertility in the Developing World. Washington, DC: National Academy Press.

Calvès, Anne-Emmanuèle. 2002. "Abortion risk and decisionmaking among young people in urban Cameroon." Studies in Family Planning 33(3): 249-260.

Eloundou-Enyegue, Parfait M. 2004. "Pregnancy-related dropouts and gender inequality in education: A life-table approach and application to Cameroon." Demography 41(3): 509-528.

Eloundou-Enyegue, Parfait M. and C. Shannon Stokes. 2004. "Teen fertility and gender inequality in education: A contextual hypothesis." Demographic Research 11(11): $305-334$.

Filmer, Deon and Lant Pritchett. 1999. "The effect of household wealth on educational attainment: evidence from 35 countries." Population and Development Review 25(1): $85-120$

Grant, Monica and Kelly Hallman. 2006. "Pregnancy-related school dropout and prior school performance in South Africa." Policy Research Division Working Paper No. 212. New York: Population Council.

Hewett, Paul C. and Cynthia B. Lloyd. 2005. "Progress towards 'Education for All': Trends and current challenges for sub-Saharan Africa." Pp. 84-117 in C.B. Lloyd, J.R. Behrman, N.P. Stromquist, and B. Cohen (eds.), The Changing Transitions to Adulthood in Developing Countries: Selected Studies. Washington, DC: National Academies Press.

Johnson-Hanks, Jennifer. 2002. "The lesser shame: Abortion among educated women in southern Cameroon." Social Science \& Medicine 5: 1337-1349.

Lloyd, Cynthia B. (ed.). 2005. Growing Up Global: The Changing Transitions to Adulthood in Developing Countries. Panel on Transitions to Adulthood in Developing Countries, National Research Council and Institute of Medicine. Washington, DC: National Academies Press. 
Lloyd, Cynthia B. 2006. "Schooling and adolescent reproductive behavior in developing countries." Paper commissioned by the United Nations Millennium Project. Available: http://www.unmillenniumproject.org/documents/CBLloyd-final.pdf

Lloyd, Cynthia B. and Barbara S. Mensch. 1999. "Implications of formal schooling for girls' transitions to adulthood in developing countries." Pp. 80-104 in C. H. Bledsoe, J. B. Casterline, J. A. Johnson-Kuhn, and J. G. Haaga (eds.), Critical Perspectives on Schooling and Fertility in the Developing World. Washington, DC: National Academy Press.

Mensch, Barbara S., Wesley H. Clark, Cynthia B. Lloyd, and Annabel S. Erulkar. 2001. "Premarital sex, schoolgirl pregnancy, and school quality in rural Kenya." Studies in Family Planning 32(4): 285-301.

Mensch, Barbara S. and Cynthia B. Lloyd. 1998. "Gender differences in the schooling experiences of adolescents in low-income countries: The case of Kenya." Studies in Family Planning 29(2): 167-184. 
Table 1 Indicators of educational and reproductive outcomes among women aged 20-24 (percent) in 20 sub-Saharan African countries

\begin{tabular}{|c|c|c|c|c|c|}
\hline & & Ever & $\begin{array}{l}\text { School exit } \\
\text { before } \\
\text { completion of } \\
\text { secondary } \\
\text { school, among } \\
\text { those who ever }\end{array}$ & $\begin{array}{l}\text { Of those } \\
\text { main reas }\end{array}$ & $\begin{array}{l}\text { eft school, } \\
\text { ported as }\end{array}$ \\
\hline & & attended & attended & Pregnancy & Marriage \\
\hline Burkina Faso & 1998-99 & 18 & 79 & 6 & 3 \\
\hline Niger & 1998 & 22 & 87 & 1 & 5 \\
\hline Mali & $1995-96$ & 23 & 85 & 3 & 13 \\
\hline Guinea & 1999 & 24 & 70 & 5 & 11 \\
\hline Chad & 1996-97 & 29 & 86 & 5 & 28 \\
\hline Benin & 1996 & 34 & 90 & 2 & 2 \\
\hline Côte d'Ivoire & 1998-99 & 53 & 82 & 4 & 2 \\
\hline Central Afr. Rep. & $1994-95$ & 58 & 88 & 15 & 5 \\
\hline Togo & 1998 & 61 & 85 & 9 & 2 \\
\hline Comoros & 1996 & 64 & 66 & 2 & 16 \\
\hline Mozambique & 1997 & 65 & 95 & 10 & 26 \\
\hline Nigeria & 1999 & 68 & 48 & 8 & 27 \\
\hline Uganda & 1995 & 78 & 90 & 8 & 6 \\
\hline Cameroon & 1998 & 79 & 83 & 12 & 7 \\
\hline Madagascar & 1997 & 82 & 94 & 2 & 10 \\
\hline Tanzania & 1996 & 83 & 95 & 4 & 16 \\
\hline Zambia & 1996-97 & 89 & 94 & 17 & 5 \\
\hline Kenya & 1998 & 96 & 69 & 13 & 11 \\
\hline Zimbabwe & 1994 & 97 & 94 & 7 & 7 \\
\hline South Africa & 1998 & 98 & 37 & 31 & 9 \\
\hline
\end{tabular}

Source: DHS data

Note: "School exit" is defined as departure from school before the completion of secondary schooling.

Countries are ranked from lowest to highest according to percent who ever attended school. 
Table 2 Percent of women aged 20-24 who gave marriage as the main reason for school exit, among those who had left school, by school attendance and marriage by age 18

\begin{tabular}{|c|c|c|c|c|}
\hline \multicolumn{5}{|c|}{ Percent marrying by age 18} \\
\hline \multirow{4}{*}{ 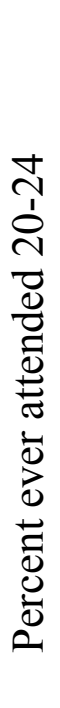 } & & $\begin{array}{l}\text { Low } \\
<30\end{array}$ & $\begin{array}{c}\text { Medium } \\
30-50\end{array}$ & $\begin{array}{l}\text { High } \\
>50\end{array}$ \\
\hline & $\begin{array}{l}\text { Low } \\
<40\end{array}$ & & $\operatorname{Benin}(2 \%)$ & $\begin{array}{c}\text { Burkina Faso (3\%) } \\
\text { Niger (5\%) } \\
\text { Mali }(13 \%) \\
\text { Guinea }(11 \%) \\
\text { Chad }(28 \%) \\
\end{array}$ \\
\hline & $\begin{array}{l}\text { Medium } \\
40-70\end{array}$ & & $\begin{array}{c}\text { Côte d'Ivoire (2\%) } \\
\text { Togo }(2 \%) \\
\text { Comoros }(16 \%) \\
\text { Nigeria }(27 \%)\end{array}$ & $\begin{array}{c}\text { C.A.R. }(5 \%) \\
\text { Mozambique (26\%) }\end{array}$ \\
\hline & $\begin{array}{l}\text { High } \\
>70\end{array}$ & $\begin{array}{c}\text { Kenya (11\%) } \\
\text { South Africa (9\%) } \\
\text { Zimbabwe }(7 \%)\end{array}$ & $\begin{array}{c}\text { Cameroon }(7 \%) \\
\text { Madagascar }(10 \%) \\
\text { Tanzania }(16 \%) \\
\text { Zambia }(5 \%)\end{array}$ & Uganda (6\%) \\
\hline
\end{tabular}

Source: Table 1 and Lloyd 2005

Table 3 Percent of women aged 20-24 who gave pregnancy as the main reason for school exit, among those who had left school, by school attendance and birth by age 18 Source: Table 1 and Lloyd 2005

\begin{tabular}{|c|c|c|c|c|}
\hline \multicolumn{5}{|c|}{ Percent giving birth by age 18} \\
\hline \multirow{4}{*}{ 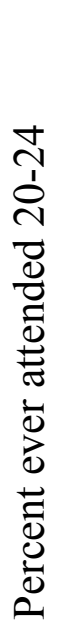 } & & $\begin{array}{l}\text { Low } \\
<25\end{array}$ & $\begin{array}{c}\text { Medium } \\
25-40\end{array}$ & $\begin{array}{l}\text { High } \\
>40\end{array}$ \\
\hline & $\begin{array}{l}\text { Low } \\
<40\end{array}$ & Benin $(2 \%)$ & Burkina Faso (6\%) & $\begin{array}{c}\text { Niger (1\%) } \\
\text { Mali (3\%) } \\
\text { Guinea (5\%) } \\
\text { Chad }(5 \%)\end{array}$ \\
\hline & $\begin{array}{l}\text { Medium } \\
40-70\end{array}$ & $\begin{array}{c}\text { Togo }(9 \%) \\
\text { Comoros }(2 \%)\end{array}$ & $\begin{array}{c}\text { Côte d'Ivoire (4\%) } \\
\text { C.A.R. (15\%) } \\
\text { Nigeria }(8 \%)\end{array}$ & Mozambique (10\%) \\
\hline & $\begin{array}{l}\text { High } \\
>70\end{array}$ & $\begin{array}{c}\text { Kenya }(13 \%) \\
\text { South Africa }(31 \%) \\
\text { Zimbabwe }(7 \%)\end{array}$ & $\begin{array}{c}\text { Cameroon }(12 \%) \\
\text { Madagascar }(2 \%) \\
\text { Tanzania }(4 \%) \\
\text { Zambia }(17 \%)\end{array}$ & Uganda $(8 \%)$ \\
\hline
\end{tabular}


Table 4 Percent of women aged 15-24 and 35-44 attending school at age 12

\begin{tabular}{lcc}
\hline & 15-24-year-olds & 35-44-year-olds \\
\hline Burkina Faso & 18.0 & 5.9 \\
Cameroon & 77.3 & 56.7 \\
Côte d'Ivoire & 41.9 & 29.0 \\
Guinea & 23.4 & 10.8 \\
Togo & 60.6 & n.a. \\
\hline
\end{tabular}

Source: DHS data

n.a. $=$ not available 
Table 5 Cumulative probability of school exit by age 20 as a result of childbirth and marriage, according to three alternative estimates of school exit by cause

\begin{tabular}{|c|c|c|c|c|c|c|}
\hline & \multicolumn{3}{|c|}{$15-24$} & \multicolumn{3}{|c|}{$35-44$} \\
\hline & 1 & 2 & 3 & 1 & 2 & 3 \\
\hline \multicolumn{7}{|l|}{ Childbirth } \\
\hline Burkina Faso & 2.6 & 3.4 & 5.0 & 2.2 & 7.3 & 9.5 \\
\hline Cameroon & 10.2 & 12.6 & 17.3 & 11.0 & 12.8 & 18.9 \\
\hline Côte d'Ivoire & 3.1 & 8.4 & 9.1 & 16.9 & 20.9 & 27.3 \\
\hline Guinea & 4.4 & 5.1 & 7.3 & 6.2 & 9.0 & 13.0 \\
\hline Togo & 6.7 & 5.4 & 9.5 & n.a. & n.a. & n.a. \\
\hline \multicolumn{7}{|l|}{ Marriage } \\
\hline Burkina Faso & 2.5 & 14.4 & 15.1 & 4.3 & 20.9 & 23.7 \\
\hline Cameroon & 4.6 & 20.8 & 22.2 & 11.6 & 26.7 & 30.6 \\
\hline Côte d'Ivoire & 1.2 & 12.0 & 12.6 & 2.7 & 20.5 & 22.0 \\
\hline Guinea & 6.6 & 10.7 & 13.3 & 21.3 & 22.4 & 32.1 \\
\hline Togo & 1.1 & 12.0 & 12.1 & n.a. & n.a. & n.a. \\
\hline
\end{tabular}

\section{Childbirth or}

Marriage

\begin{tabular}{lrrrrrr} 
Burkina Faso & 5.1 & 17.8 & 20.1 & 6.5 & 28.2 & 33.2 \\
Cameroon & 14.8 & 33.4 & 39.5 & 22.6 & 39.5 & 49.5 \\
Côte d'Ivoire & 4.3 & 20.4 & 21.7 & 19.6 & 41.4 & 49.3 \\
Guinea & 11.0 & 15.8 & 20.6 & 27.5 & 31.4 & 45.1 \\
Togo & 7.8 & 17.4 & 21.6 & n.a. & n.a. & n.a. \\
\hline
\end{tabular}

Note:

Estimate 1 - reported reason for leaving school-pregnancy or marriage

Estimate 2 - childbirth or marriage occurring at same age as, or age $+/$ - one year before or after leaving school

Estimate 3 - women who fit criteria for either or both estimates 1 and 2 n.a. = not available.

Source: DHS data 
Table 6 Individual, household, and community characteristics of women aged 15-24 used as independent variables in regressions (sample restricted to those in school at age 12)

\begin{tabular}{lccccc}
\hline & $\begin{array}{c}\text { Burkina } \\
\text { Faso }\end{array}$ & Cameroon & $\begin{array}{c}\text { Côte } \\
\text { d'Ivoire }\end{array}$ & Guinea & Togo \\
\hline $\begin{array}{l}\text { Individual } \\
\quad \text { Premarital sex before age } 20\end{array}$ & 44.6 & 69.0 & 75.9 & 42.4 & 71.5 \\
$\quad$ (among 20-24) \% & & & & & \\
$\quad$ Grade-for-age index (low) \% & 6.4 & 16.2 & 12.2 & 18.5 & 59.4 \\
$\quad$ Grade-for-age index (middle)\% & 35.5 & 32.3 & 46.2 & 40.3 & 33.5 \\
$\quad$ Grade-for-age index (high)\% & 58.1 & 51.5 & 41.6 & 40.2 & 7.1 \\
Household & & & & & \\
$\quad$ Wealth index (low) \% & 9.6 & 23.2 & 13.9 & 5.1 & 22.2 \\
$\quad$ Wealth index (middle) \% & 20.2 & 47.2 & 42.6 & 30.9 & 36.7 \\
$\quad$ Wealth index (high) \% & 70.2 & 29.6 & 43.5 & 64.0 & 41.1 \\
$\quad$ Education of household head & 3.6 & 6.4 & 6.1 & 6.1 & 4.9 \\
$\quad$ (mean grade attained) & & & & & \\
Community & & & & & \\
$\quad$ Urban (versus rural) \% & 65.7 & 43.5 & 64.1 & 79.1 & 53.6 \\
\hline
\end{tabular}

Source: DHS data 
Table 7 Odds ratios for school exit by various characteristics, according to discrete-time hazard models (sample restricted to those in school at age 12)

\begin{tabular}{|c|c|c|c|c|c|}
\hline & $\begin{array}{c}\text { Burkina } \\
\text { Faso }\end{array}$ & Cameroon & $\begin{array}{c}\text { Côte } \\
\text { d'Ivoire }\end{array}$ & Guinea & Togo \\
\hline \multicolumn{6}{|l|}{ Individual } \\
\hline Age: 13 (versus 12) & 1.31 & $1.95 * * *$ & 1.32 & 1.02 & 1.24 \\
\hline 14 (versus 12) & $2.29 * * *$ & $3.39 * * *$ & $2.37 * * *$ & 1.02 & $1.84 * * *$ \\
\hline 15 (versus 12 ) & $3.50 * * *$ & $5.15 * * *$ & $3.15 * * *$ & 0.982 & $2.74 * * *$ \\
\hline 16 (versus 12 ) & $2.46^{* * *}$ & $5.35 * * *$ & 1.14 & 1.02 & $2.61 * * *$ \\
\hline 17 (versus 12) & $2.93 * * *$ & $5.58 * * *$ & 1.36 & 0.872 & $3.90 * * *$ \\
\hline 18 (versus 12 ) & $4.18 * * *$ & $6.08 * * *$ & 1.27 & 0.77 & $4.47 * * *$ \\
\hline $19($ versus 12$)$ & $3.18 * * *$ & $6.69 * * *$ & 0.95 & 1.20 & $4.12 * * *$ \\
\hline $\begin{array}{l}\text { Had premarital sex (versus ne } \\
\text { had sex or initiated sex at } \\
\text { marriage) }\end{array}$ & 1.46 & $2.33 * * *$ & $2.72 * * *$ & $2.01 * * *$ & $1.70 * * *$ \\
\hline \multicolumn{6}{|l|}{ Grade-for-age index } \\
\hline Low (versus high) & 1.04 & $1.55 * * *$ & $1.76^{* *}$ & 1.08 & $1.48 * *$ \\
\hline Middle (versus high) & $0.68 *$ & $1.29 * * *$ & $1.49 * *$ & $0.69 * *$ & 0.84 \\
\hline \multicolumn{6}{|l|}{ Household } \\
\hline \multicolumn{6}{|l|}{ Wealth index } \\
\hline Middle (versus low) & 1.12 & $0.76 * * *$ & 1.39 & 0.68 & $0.82 * *$ \\
\hline High (versus low) & $0.53 * *$ & $0.52 * * *$ & 0.79 & $0.46^{* *}$ & $0.61 * * *$ \\
\hline $\begin{array}{l}\text { Education of household head } \\
\text { (mean grades attained) }\end{array}$ & $0.93 * * *$ & $0.96 * * *$ & $0.97 * *$ & $0.98 * *$ & 0.99 \\
\hline \multicolumn{6}{|l|}{ Community } \\
\hline Urban (versus rural) & $0.47 * * *$ & $0.66 * * *$ & $0.60 * * *$ & 0.90 & 1.02 \\
\hline $\mathrm{N}$ & 617 & 1,975 & 700 & 594 & 1,869 \\
\hline Person Years & 3,000 & 10,329 & 3,244 & 2,967 & 9,567 \\
\hline Pseudo $\mathrm{R}^{2}$ & 0.10 & 0.12 & 0.08 & 0.03 & 0.07 \\
\hline \multicolumn{6}{|l|}{$\mathrm{p}<0.01 * * *$} \\
\hline $\begin{array}{l}\mathrm{p}<0.05 * * \\
\mathrm{p}<0.10 *\end{array}$ & & & & & \\
\hline
\end{tabular}


Table 8 Odds ratios for first marriage by various characteristics, according to discretetime hazard models (sample restricted to those in school at age 12)

\begin{tabular}{|c|c|c|c|c|c|}
\hline & $\begin{array}{c}\text { Burkina } \\
\text { Faso }\end{array}$ & Cameroon & $\begin{array}{c}\text { Côte } \\
\text { d'Ivoire }\end{array}$ & Guinea & Togo \\
\hline \multicolumn{6}{|l|}{ Individual } \\
\hline Age: 13 (versus 12) & 1.65 & $3.60 * * *$ & $4.49 * *$ & 1.42 & $6.37 * * *$ \\
\hline $14($ versus 12$)$ & 2.57 & $7.41 * * *$ & $16.34 * * *$ & $5.71 * * *$ & $9.71 * * *$ \\
\hline 15 (versus 12 ) & $13.70 * *$ & $11.57 * * *$ & $30.82 * * *$ & $9.21 * * *$ & $14.75 * * *$ \\
\hline 16 (versus 12 ) & $24.56 * * *$ & $15.39 * * *$ & $29.06 * * *$ & $11.07 * * *$ & $20.35 * * *$ \\
\hline 17 (versus 12) & $65.12 * * *$ & $18.99 * * *$ & $34.70 * * *$ & $10.97 * * *$ & $31.21 * * *$ \\
\hline 18 (versus 12 ) & $51.02 * * *$ & $23.03 * * *$ & $26.13 * * *$ & $11.56^{* * *}$ & $32.25 * * *$ \\
\hline 19 (versus 12) & $99.01 * * *$ & $17.78 * * *$ & $34.54 * * *$ & 12.59 & $36.66^{* * *}$ \\
\hline $\begin{array}{l}\text { Had premarital sex (versus } \\
\text { never had sex or initiated } \\
\text { sex at marriage) }\end{array}$ & $1.53 *$ & $1.91 * * *$ & $2.06 * * *$ & 1.30 & $2.28 * * *$ \\
\hline \multicolumn{6}{|l|}{ Grade-for-age index } \\
\hline Low (versus high) & $2.17 * *$ & $1.51 * * *$ & 1.58 & 0.79 & 1.60 \\
\hline Middle (versus high) & 1.37 & $1.26^{* *}$ & 0.96 & 0.72 & 1.15 \\
\hline \multicolumn{6}{|l|}{ Household } \\
\hline \multicolumn{6}{|l|}{ Wealth index } \\
\hline Middle (versus low) & 0.78 & 0.92 & 0.90 & $0.58 *$ & $0.79 *$ \\
\hline High (versus low) & $0.47 * *$ & 0.79 & $0.30 * * *$ & $0.31 * * *$ & $0.53 * * *$ \\
\hline $\begin{array}{l}\text { Education of household head } \\
\text { (mean grades attained) }\end{array}$ & $0.93 * * *$ & 0.99 & 1.01 & 0.99 & 1.02 \\
\hline \multicolumn{6}{|l|}{ Community } \\
\hline Urban (versus rural) & $0.54 * *$ & $0.61 * * *$ & $0.60^{* *}$ & $0.67 *$ & $0.53 * * *$ \\
\hline $\mathrm{N}$ & 615 & 1,966 & 698 & 592 & 1,858 \\
\hline Person Years & 3,742 & 11,803 & 4,324 & 3,361 & 11,462 \\
\hline Pseudo $\mathrm{R}^{2}$ & 0.23 & 0.12 & 0.14 & 0.09 & 0.13 \\
\hline \multicolumn{6}{|l|}{$\mathrm{p}<0.01 * * *$} \\
\hline \multicolumn{6}{|l|}{$\mathrm{p}<0.05 * *$} \\
\hline
\end{tabular}


Table 9 Odds ratios for first birth by various characteristics, according to discrete-time hazard models (sample restricted to those in school at age 12)

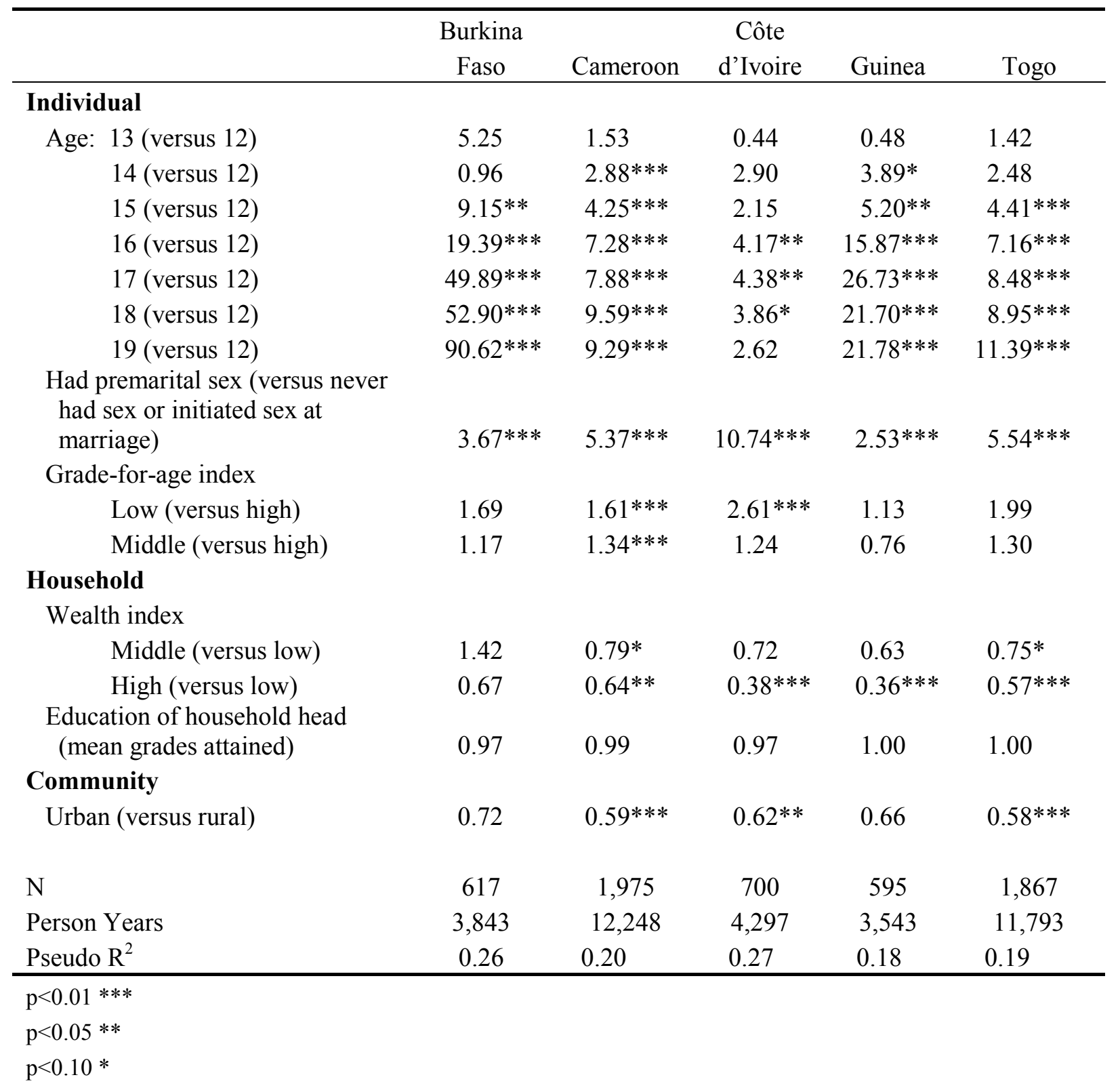


Figure 1 Cumulative risk of school exit attributable to childbirth or marriage among 15-24-year-olds attending school at age 12
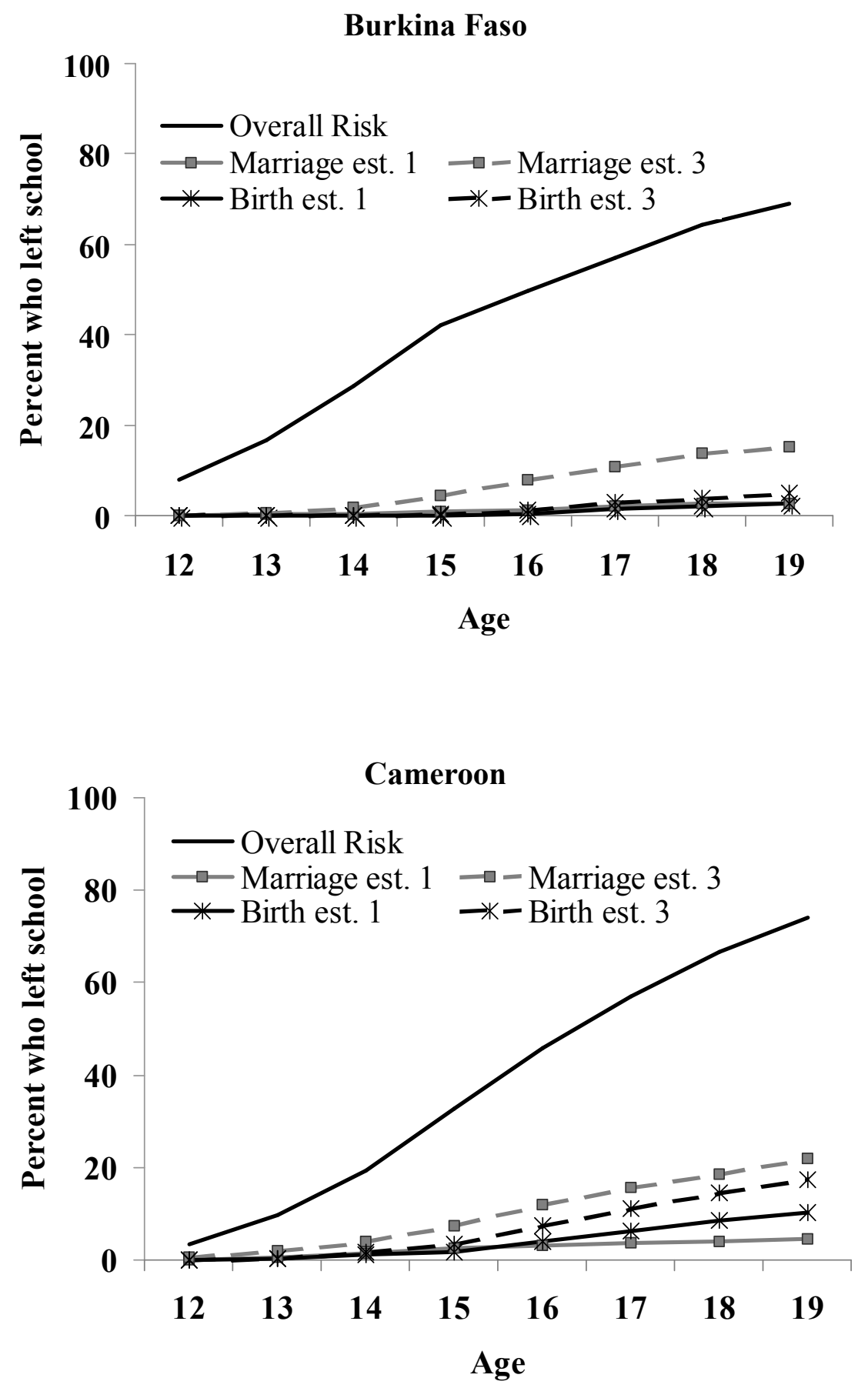
Figure 1 (continued)
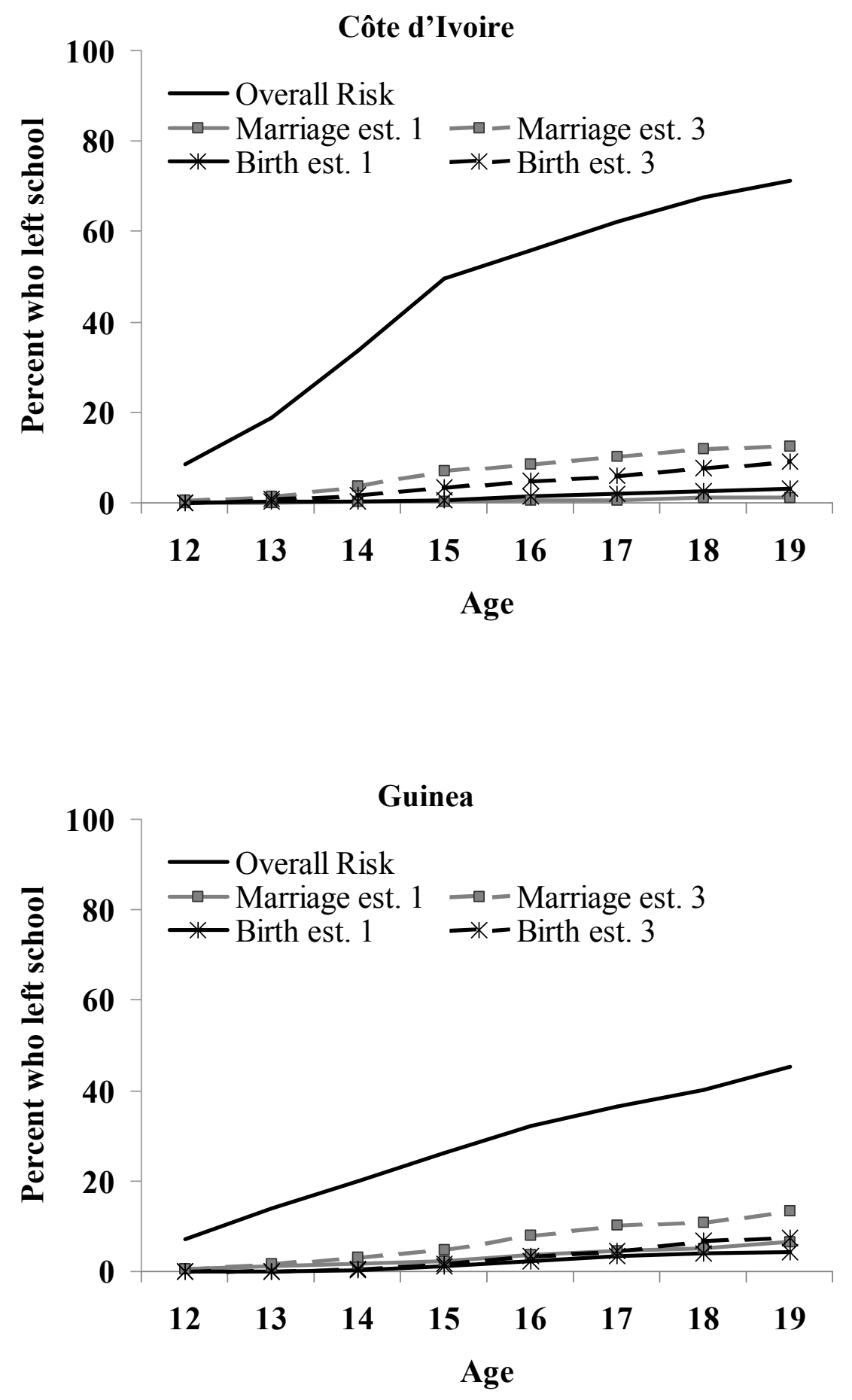
Figure 1 (continued)

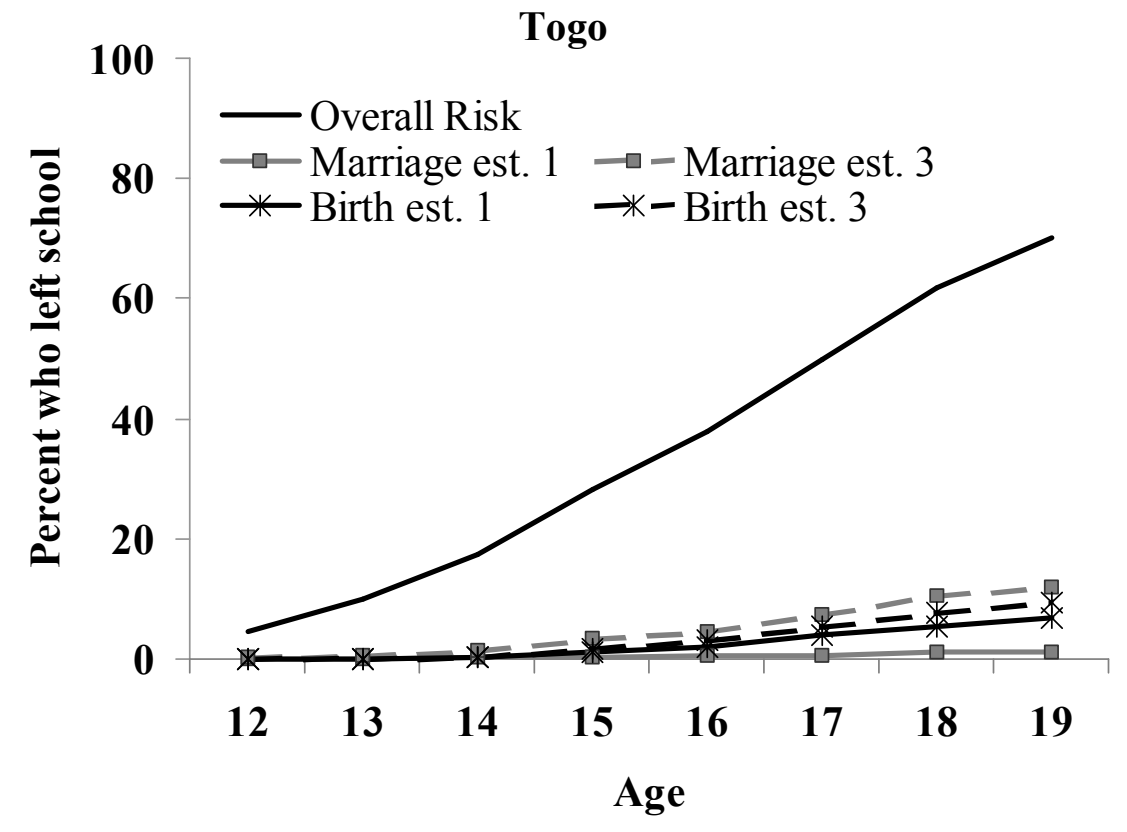


Figure 2 Cumulative risk of school exit attributable to childbirth or marriage, by age group, highest estimate

\section{Burkina Faso}

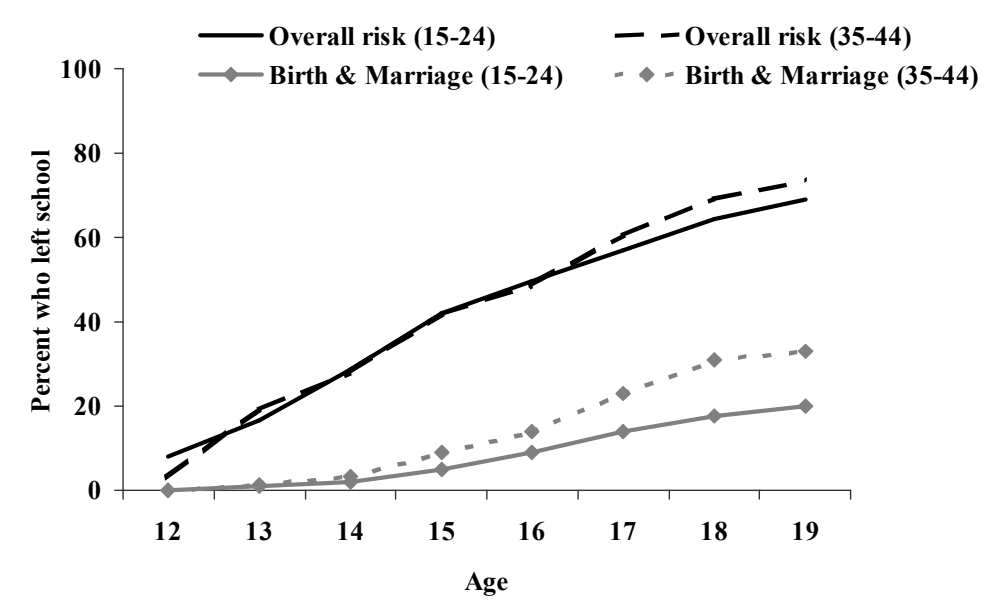

Cote d'Ivoire

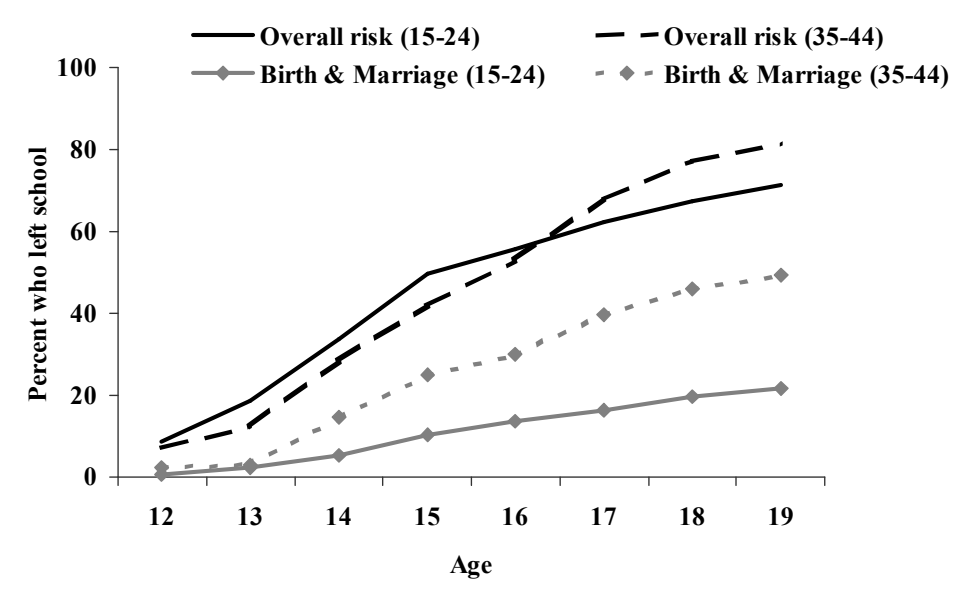

Cameroon

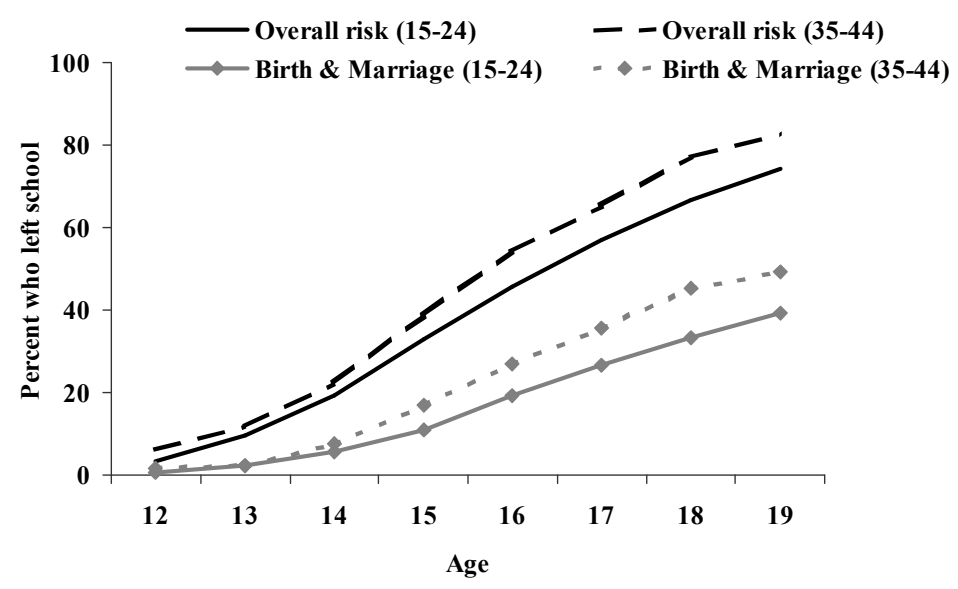

Guinea

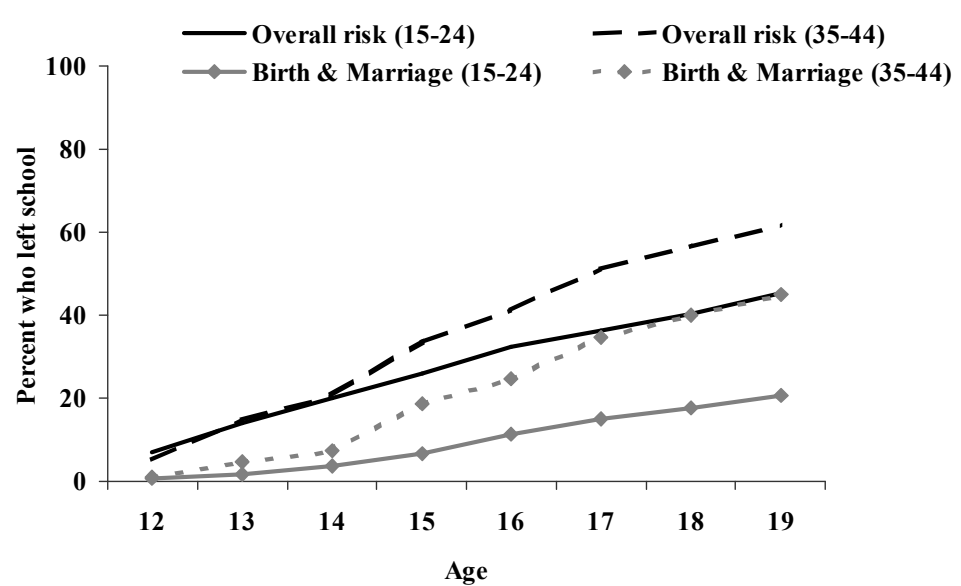




\section{POLICY RESEARCH DIVISION WORKING PAPERS}

If still in print, single copies of up to three working papers from 1989 through 2003 are available free of charge.

Beginning with the 2004 issues, working papers are no longer available in print format. Instead they are distributed electronically. As each new paper is completed subscribers are notified by e-mail and a link to the paper is provided.

To subscribe to the Policy Research Division working paper e-mail notification list, or to obtain back issues from 1989 to 2003, please send your request to prdwp@popcouncil.org.

PDFs of recent issues are available at www.popcouncil.org/publications/wp/prd/rdwplist.html

2006

219 Cynthia B. Lloyd and Barbara S. Mensch, "Marriage and childbirth as factors in school exit: An analysis of DHS data from subSaharan Africa."

218 Ayaga A. Bawah, James F. Phillips, Martin Adjuik, Maya Vaughan-Smith, Bruce MacLeod, and Fred N. Binka, "The impact of immunization on the association between poverty and child survival: Evidence from KassenaNankana District of northern Ghana."

217 Zachary Zimmer, "Poverty, wealth inequality, and health among older adults in rural Cambodia."

216 John Bongaarts, "Late marriage and the HIV epidemic in subSaharan Africa."

215 John Bongaarts, "How long will we live?"

214 Zachary Zimmer, Toshiko Kaneda, and Laura Spess, "Urban versus rural mortality among older adults in China."
213 Paul Demeny and Geoffrey McNicoll, "The political demography of the world system, 2000-2050."

212 Monica Grant and Kelly Hallman, "Pregnancy-related school dropout and prior school performance in South Africa."

211 Kelly Hallman, Sara Peracca, Jennifer Catino, and Marta Julia Ruiz, "Multiple disadvantages of Mayan females: The effect of gender, ethnicity, poverty, and residence on education in Guatemala."

210 Geoffrey McNicoll, "Policy lessons of the East Asian demographic transition."

209 Cynthia B. Lloyd, Cem Mete, and Monica J. Grant, "The implications of changing educational and family circumstances for children's grade progression in rural Pakistan: 1997-2004." 
199 Zachary Zimmer, Linda G.

208 James F. Phillips, Ayaga A. Bawah, and Fred N. Binka, "Accelerating reproductive and child health program development: The Navrongo Initiative in Ghana."

207 John Bongaarts and Griffith Feeney, "The quantum and tempo of life-cycle events."

206 Barbara S. Mensch, Monica J. Grant, and Ann K. Blanc, "The changing context of sexual initiation in sub-Saharan Africa."

205 Geoffrey McNicoll, "Population and sustainability."

204 John Bongaarts, "The causes of stalling fertility transitions."

203 Ayaga A. Bawah and Fred N. Binka, "How many years of life could be saved if malaria were eliminated from a hyperendemic area of northern Ghana?"

202 Barbara S. Mensch, Susheela Singh, and John B. Casterline, "Trends in the timing of first marriage among men and women in the developing world."

201 Zachary Zimmer, "Active life expectancy and functional limitations among older Cambodians: Results from a 2004 survey."

200 Brian Wells Pence, Philomena Nyarko, James F. Phillips, and Cornelius Debpuur, "The effect of community nurses and health volunteers on child mortality: The Navrongo Community Health and Family Planning Project."

197 Kristine R. Baker, Mary Beth Ofstedal, Zachary Zimmer, Zhe Tang, and Yi-Li Chuang, "Reciprocal effects of health and economic well-being among older adults in Taiwan and Beijing."

196 Mark R. Montgomery and Paul C. Hewett, "Poverty and children's schooling in urban and rural Senegal."

2004

195 Luciana Suran, Sajeda Amin, Lopita Huq, and Kobita Chowdury, "Does dowry improve life for brides? A test of the bequest theory of dowry in rural Bangadesh."

194 Barbara S. Mensch, Monica J. Grant, Mary P. Sebastian, Paul C. Hewett, and Dale Huntington. "The effect of a livelihoods intervention in an urban slum in India: Do vocational counseling and training alter the attitudes and behavior of adolescent girls?"

193 Amanda Ritchie, Cynthia B. Lloyd, and Monica Grant. "Gender differences in time use among adolescents in developing countries: Implications of rising school enrollment rates." 
192 John Bongaarts. "Long-range trends in adult mortality: Models and projection methods."

191 John Koku Awoonor-Williams, Ellie S. Feinglass, Rachel Tobey, Maya N. Vaughan-Smith, Frank K. Nyonator, Tanya C. Jones, and James F. Phillips, "Bridging the gap between evidence-based innovation and national healthsector reform in Ghana."

190 Kelly Hallman, "Socioeconomic disadvantage and unsafe sexual behaviors among young women and men in South Africa."

189 Toshiko Kaneda, Zachary Zimmer, and Zhe Tang, "Differentials in life expectancy and active life expectancy by socioeconomic status among older adults in Beijing."

188 Cynthia B. Lloyd and Monica J. Grant, "Growing up in Pakistan: The separate experiences of males and females."
187 Zachary Zimmer, Xianghua Fang, Toshiko Kaneda, Zhe Tang, and Julia Kwong. "Trends and transitions in children's coresidence with older adults in Beijing municipality."

186 Sajeda Amin and Alaka M. Basu. "Popular perceptions of emerging influences on mortality and longevity in Bangladesh and West Bengal."

185 John Bongaarts. "Population aging and the rising cost of public pensions."

184 Mark R. Montgomery and Paul C. Hewett. "Urban poverty and health in developing countries: Household and neighborhood effects." 